\title{
Existencia gloriosa de Jesús en los ejercicios ignacianos
}

\author{
Rogelio García Mateo S.I.
}

\section{Sumario:}

Desde hace un tiempo, el autor viene escribiendo en diversas revistas, entre ellas ATG, una síntesis teológico-espiritual de la figura de Cristo en los Ejercicios espirituales según san Ignacio de Loyola [EE]. En esta ocasión se refiere a la meditación, consideración y contemplación del Cristo Resucitado y para ello presenta las trece apariciones del Señor según el libro de los Ejercicios [EE 299-311], desde la primera a la Virgen su madre [EE 219, 220 y 299], hasta la décimotercera y última [EE 311]. El autor va anotando el texto ignaciano con las oportunas referencias escriturísticas y sobre todo con las de particular interés de clásicos de la espiritualidad ignaciana y autores espirituales como Ludolfo el Cartujano, Luis de la Puente, Antonio Orbe u otros teólogos actuales.

\section{Palabras clave:}

apariciones de Cristo, Ejercicios espirituales, elección, pascua, relatos, Resucitado

\begin{abstract}
:
The author has been publishing since some time back in diverse reviews, among them the ATG, a theological-spiritual synthesis of the figure of Christ in the Spiritual Exercises of Saint Ignatius of Loyola [EE]. This time he refers to the meditation, consideration and contemplation of the Risen Christ, and for this purpose he presents the thirteen apparitions of the Lord, as contained in the book of the Exercises [EE 299-311], from the first, to the Blessed Virgin Mary, His Mother [EE 219, 220 and 299], until the thirteenth and last one [EE 311]. The author goes ahead to study the Ignatian text with the opportune scripture references and above all with the ones of particular interest to the classics of the Ignatian spirituality and to the authors of spirituality like Ludolf the Cartusian, Luis de la Puente, Antonio Orbe, or some other present day theologians.
\end{abstract}

\section{Keywords:}

apparitions of Christ, Spiritual Exercices election, Easter Time, accounts, Risen Christ.

\section{Introducción}

La tercera y la cuarta semana de los Ejercicios continúan teniendo como finalidad el "conocimiento interno de Cristo que por mí se ha hecho hombre para que más le ame y le siga" (EE $\left.{ }^{1} 104\right)$; pero con objetivos específicos. Si

\footnotetext{
${ }^{1}$ Con esta sigla se citan los Ejercicios espirituales de san Ignacio de Loyola.
} 
en la tercera es la unión con Cristo sufriente (EE 203)2 ${ }^{2}$, el objetivo de la cuarta es la unión con Cristo glorioso. Por ello, se puede decir, que ambas semanas ayudan particularmente a hacer una experiencia personal del misterio pascual. Pablo define la gracia propia de la resurrección como un don de vida en Cristo, que "ha resucitado para nuestra justificación" $(\mathrm{Rm} 4,25)$. La justificación consiste, por tanto, no solo en la muerte al pecado por la unión con la muerte de Cristo, sino también en una vida nueva por la unión con su resurrección $(\mathrm{Rm} 5,9)$. Resulta evidente que en este contexto pascual el objetivo propio de esta cuarta etapa es el de experimentar una alegría profunda y extraordinaria: "pedir gracia para me alegrar y gozar intensamente de tanta gloria y gozo de Cristo nuestro Señor" (EE 221).

Nadie fue testigo ocular de este acontecimiento, ni podía serlo, porque se trata precisamente de una realidad escatológica, de un misterio que supera las coordenadas históricas del tiempo y del espacio y, sin embargo, tuvo referencias históricas comprobadas. Nadie puede decir cómo sucedió; ningún evangelista lo describe, afirman que el sepulcro estaba vacío y narran "apariciones" del Resucitado en las que se trasluce esta cualidad histórico-trascendente, cuya peculiaridad las caracteriza. En ellas, como se verá, el Resucitado sale al encuentro, bendice, habla, enseña, consuela. Los discípulos reaccionan unas veces con sorpresa y alegría otras con duda, incredulidad y miedo. De aquí que no se las puede calificar de experiencias simplemente subjetivas o místicas ${ }^{4}$. Los estudios exegéticos y teológicos han resaltado cómo las apariciones del Resucitado se presentan según el modelo de las teofanías del AT, o sea, como formas de revelación del misterio divino 5 .

${ }^{2}$ R. García Mateo, “Teología de la cruz en Ignacio de Loyola": Estudios Eclesiásticos 92 (2017) 133-161.

${ }^{3}$ Luis de la Puente en su amplio comentario a los Ejercicios resalta cómo la cuarta semana está dentro de la vía unitiva en cuanto lleva a "gozar de la unión con su infinita bondad y voluntad [...]. Y aunque es verdad que la contemplación y unión tiene por blanco principal la divinidad y perfecciones de Dios, con quien se hace un espíritu, mas también mira la humanidad de Dios encarnado y sus esclarecidas obras y virtudes, en las cuales resplandecen las excelencias de la divinidad; porque, como el mismo Señor dijo, la vida eterna, no solamente consiste en conocer a Dios vivo y verdadero, sino también a su Hijo Jesucristo... Y los que quieren excluir siempre de la contemplación los misterios de su sacratísima humanidad, serán excluidos de gozar los frutos y regalos de la vida eterna". Cf: Meditaciones de los misterios de nuestra santa fe, Madrid 1950, Apostolado de la Prensa, t.2, 447.

${ }^{4}$ Las apariciones del Resucitado, que se narran en el NT, no se deben confundir con vivencias interiores que han tenido místicos y santos, y mucho menos con alucinaciones o sueños paranormales. Ya en Pablo, como veremos, se halla una diferencia fundamental entre sus experiencias místicas hasta el tercer cielo (2Cor 12,1-4) y el decisivo encuentro con el Resucitado camino de Damasco.

${ }^{5}$ W. KASPER, Jesús el Cristo, Salamanca 1979, Sígueme, 170ss. 
En los Ejercicios están elencadas, reuniendo los pasajes pascuales de los cuatro evangelios y de 1 Cor 15,1-8. Sin detenerse a examinar las diferencias de un evangelista a otro, ni a distinguir unas tradiciones de otras, como haría un estudio exegético, Ignacio coloca, como lo ha hecho hasta ahora en los misterios de la vida terrena de Jesús (EE 261-298), un versículo tras otro, citando explícitamente de cuál evangelista está tomado. Cada misterio se resume de un modo casi telegráfico en tres puntos "para meditar y contemplar en ellos con mayor facilidad" (EE 261).

\section{La mujer primer testigo de la resurrección}

Los Ejercicios explican la muerte de Cristo por la separación del alma y del cuerpo: "después que Cristo espiró en la cruz, y el cuerpo quedó separado del ánima y con él siempre unida la Divinidad, la ánima beata descendió al infierno, asimismo unida con la Divinidad, de donde sacando a las ánimas justas y veniendo al sepulcro y resucitado, apareció a su bendita Madre en cuerpo y ánima" (EE 219). En esto sigue Ignacio en lo esencial la explicación de la patrística. Gregorio de Nisa afirma: "Por la unidad de la naturaleza divina que permanece presente en cada una de las dos partes del hombre, las que antes estaban separadas y segregadas, estas se unen de nuevo. Así la muerte se produce por la separación del compuesto humano, y la Resurrección por la unión de las dos partes separadas" ${ }^{\text {. }}$

Se trata, sin embargo, de una separación sui generis, ya que la divinidad, como requiere la unión hipostática desde la Encarnación, en ningún momento se separó ni del ánima ni del cuerpo. Con todo, Jesús experimentó, como cualquier mortal el poder aniquilante de la muerte, llegó hasta lo último en su realidad humana, compartiendo el destino de todos los que mueren, pero al mismo tiempo, al estar unido a la Divinidad, ha eliminado la amenaza que convertía a la muerte en un mal sin fin, reduciéndola a un tránsito para la gloria e incentivando la salvación de las "ánimas justas" que se encontraban en los infiernos desde Adán y Eva ${ }^{7}$ a la espera de un Redentor que las condujese a la gloria del Padre.

${ }^{6}$ Citado en el Catecismo de la Iglesia Católica n.650; cf. también DS 325; 356.

${ }^{7}$ Los infiernos (sheol) es el lugar de las tinieblas, del olvido, en lo más profundo de la tierra (Dt 32,22). Y aunque el mundo era percibido como manifestación del poder divino, sin embargo, la muerte y el sufrimiento injustos interrogan a Dios, como se argumenta en el libro de Job. 
Los evangelios no hablan del encuentro del Jesús glorioso con su madre; sin embargo, de este silencio Ignacio no concluye que el Resucitado no se apareciera a ella: "Primero apareció a la Virgen María, lo cual aunque no se diga en la Escritura, se tiene por dicho, en decir que apareció a tantos otros. Porque la Escritura supone que tenemos entendimiento. Según está escrito: (¿También vosotros estáis sin entendimiento?) ") (EE 299). Se muestra bien así que, pese a su aprecio por la Sagrada Escritura como fuente principal de la fe cristiana, ella no es el único criterio. Testimonio fundamental de la fe respecto a la Biblia son también la praxis de la Iglesia, la Tradición y la reflexión teológica ${ }^{9}$, a la cual apela Ignacio apoyándose, a su vez, en la Escritura con la frase de Mt 15,16: “¿También vosotros tenéis tampoco intelecto?”, o sea, es la misma Escritura la que autoriza a no quedarse en el literalismo textual.

La fe cristiana advirtió pronto que así como María fue partícipe del dolor del crucificado, así debió ser la primera en gozar y alegrarse con la gloria del Resucitado. Efrén sirio (+ 373) ofrece uno de los primeros testimonios de la aparición de Jesús a su Madre. El Cartujano recoge esta tradición:

"E como la bienaventurada Reina del cielo supo de cierta ciencia que ya su hijo no estaba en el sepulcro, mas que era resucitado y hecho inmortal e impasible, no quiso ir al monumento... retrájose en retraimiento de soledad de llorosa criatura...Pues estando de este semblante... aparecióle el Príncipe de la gloria, Jesucristo, su amantísimo Hijo, vestido de vestiduras muy blancas de gloriosa refulgencia... E estuvo delante de ella con cara serena, más hermoso que los cielos, más glorioso que el paraíso y más alegre que todos los ángeles, todo festival y triunfante...Y en el punto que lo vio, levantóse, no mudando las lágrimas, mas mudando la causa de ellas, y abrázolo y ansí convertió los lloros de dolor penoso en lágrimas de glorioso descanso y de alegría de no mudable perpetuidad"(p. 297) ${ }^{10}$.

La fe de María sabe que Dios derriba del trono a soberbios y poderosos y enaltece a los humildes e injustamente abatidos (Lc 1,52). Viendo al Hijo agonizar y morir, María reviviría intensamente la esperanza de que Dios es

${ }^{8}$ En los Ejercicios se usa el paréntesis en lugar de las comillas.

${ }^{9}$ Constitución dogmática del Concilio Vaticano II Dei Verbum n. 24.

10 Nos referiremos frecuentemente a esta gran obra, cuyo título reza "Vita Christi Cartujano". Ignacio la leyó durante la convalecencia de la herida de Pamplona; de esa extrajo no pocos pasajes, según se afirma en su relato autobiográfico (n. 11). Por tanto, esta obra, que costa de dos partes en cuatro volúmenes y cuyo autor fue el cartujo alemán Ludolfo de Sajonia, proporciona en la traducción castellana del franciscano y literato Ambrosio Montesinos, un contexto espiritual y teológico muy cercano a los Ejercicios ignacianos. Cf. R. GARCía MateO, El misterio de la vida de Cristo en los Ejercicios ignacianos y en el Vita Christi Cartujano. Antología de textos, Madrid 2002. Se cita con la abreviatura "Cartujano". 
capaz de dar la vida a los muertos (Heb 11,19; Rm 4,17). El encuentro con su Hijo resucitado no pudo ser otra cosa que una experiencia de fe pascual, que en ella comenzó con el misterio de la encarnación, en particular desde el día en que Simeón le preanunció el destino doliente de su Hijo (EE 268). Citando a San Ambrosio, el Cartujano continúa: "Vio la gloriosísima Virgen Madre la resurrección del Señor, porque así como primero la creyó, así primero la vio".

La segunda aparición, según el orden de los Ejercicios, parte de Mc 16, 1-11. El día siguiente al sábado unas mujeres se dirigen al sepulcro de Jesús para embalsamar su cuerpo; "van muy de mañana María Magdalena, Jacobi y Salomé, al monumento, diciendo: (¿Quién nos alzará la piedra de la puerta del monumento?)"; pero he aquí que "ven la piedra alzada y al ángel que dice: (A Jesús nazareno buscáis; ya es resucitado, no está aquí)" (EE 300). Encuentran una tumba vacía y un ángel cuando lo que querían era embalsamar el cadáver de Jesús. No preguntan nada, pero el ángel conoce sus intenciones y les anuncia la insólita gran noticia de que Jesús ha resucitado, no está allí su cadáver. El texto evangélico continúa: "Pero id a decir a sus discípulos y a Pedro que irá delante de vosotros a Galilea; allí le veréis, como os dijo. Se salieron del sepulcro con gran temblor y espanto, y no dijeron nada a nadie porque tenían miedo" (Mc 16,7-8). El Cartujano interpreta esta reacción como consecuencia de la estupefacción que ellas sufrieron al no encontrar el cuerpo de Jesús:

"E las mujeres, cuando se vieron ajenas de su deseo y privadas de su esperanza, a causa de que no hallaron el cuerpo del Señor que esperaban hallar, no entendiendo ni mirando a las palabras que del ángel habían oído, espantadas del no acostumbrado aparecimiento de los ángeles, suspirando y gimiendo, porque no habían hallado a su Señor, tornáronse para los discipulos diciendo: llevado se han al Señor del monumento y no sabemos a dónde lo pusieron..." (p.301).

A estas circunstancias de desconcierto y temor se añade un tercer punto tomado del cuarto evangelio: "apareció a María, la que se quedó cerca del sepulcro, después de idas las otras". Llorando al ver que el cadáver de Jesús no se encuentra (Jn 20,13), se dirige a uno, que parece trabajar de hortelano, diciéndole: "Si tú te lo llevaste, dime dónde le pusiste" (Jn 20,14), o sea, en su aflicción no reconoce al Resucitado; solo a la voz de Jesús que llama a María por su nombre lo reconoce, exclamando: (Rabboni, que quiere decir: oh buen Maestro). Orígenes, comenta:

"Luego esta bienaventurada mujer, testigo primero de la santa resurrección, corrió con aceleramiento y derribóse a los pies del Señor, adorando sus pisadas, y luego quiso abrazar por devoción los lugares donde ponía sus santísimos pies, reconociéndolo, los quiso tocar y besar según que lo tenía por 
costumbre antes de su pasión [...] Más quiero ( le dijo Jesús) que llegues a mí por tañimiento de corazón y de fe, creyendo que yo soy igual al Padre, que por tañimiento corporal, creyendo que yo soy hombre puro y menor que el Padre, porque aún no creía ella con perfecto corazón en él, pues que lo lloraba como a hombre que no fuera Dios" (Cartujano p.304).

El encuentro termina con un mensaje de Jesús para los apóstoles: "Ve a mis hermanos, y diles: Subo a mi Padre y a vuestro Padre, a mi Dios y a vuestro Dios". Con la Resurrección se produce un profundo cambio en la relación de Jesús con sus discípulos: ya no son simples discípulos ni solo "amigos" (Jn 14,15), sino que han sido elevados a "hermanos" suyos, o sea, a "hijos de Dios". Jesús extiende a ellos su propia filiación divina, como ya les había enseñado en la oración del Padrenuestro. En el Cartujano se distingue teológicamente entre ambas filiaciones: "Anda, ve reformada, ya de fe y alegría y notifica a los apóstoles, mis hermanos, que resucité y que muy presto subiré a mi Padre natural y Padre vuestro por gracia; Dios mío, porque creó mi humanidad, a cuya obediencia yo estoy sujeto en cuanto hombre, y Dios vuestro, porque os crió y libró de todo error, y entre vosotros y Él yo soy pacífico medianero...." (p. 305). A. Orbe, imaginando la reacción de la Magdalena a las palabras del Resucitado, dice:

"Maestro mío, he creído entender que, con tu recado, les he de igualar contigo, frente al Dios y Padre. ¿Te he entendido bien? - Y Jesús habría podido responderle : 'Entendiste bien, aunque en su día lo entenderás mejor. Todo el misterio está en mi Carne: ayer rediviva, y hoy hecha Dios para bien de mis hermanos" " ${ }_{11}$.

Sin subir aún al Padre, ni estar entre los hombres como antes, pero sin perder la unión hipostática, aparecía y desaparecía, se daba a conocer a sus discípulos haciendo "el oficio de consolar" (EE 224).

La tercera aparición de los Ejercicios se corresponde con Mt 28. En Mt 27, 62-64 se relata cómo los sumos sacerdotes y los fariseos piden a Pilato que el sepulcro sea sellado con una losa y custodiado por guardias, pero se produjo un gran temblor de tierra, un ángel hizo rodar la losa, y se sentó sobre ella. La piedra corrida significa que con la resurrección de Cristo, se han abierto las puertas del lugar de los muertos (EE 218). El ángel dice a las mujeres, no temáis. "Sé que buscáis a Jesús, el Crucificado. No está aquí. Resucitó, como anunció. Mirad el lugar donde reposó. Id a toda prisa a anunciar a sus discípulos que ha resucitado de entre los muertos. Y sabed que se os adelanta camino de Galilea" (Mt 28, 5-6). "Salen estas Marías del monumento con temor y

${ }^{11}$ A. ORBE, Vísperas de Ascensión. Meditaciones sobre la vida gloriosa de Jesús, Barcelona 1990, 123. 
gozo grande, queriendo anunciar a los discípulos la resurrección del Señor" (EE 301,1). Son vivencias parecidas a lo que ha narrado Marcos; pero ahora con la diferencia de que las mujeres sienten, sí, el desconcierto del temor ante el sepulcro vacío, pero también gozo con el encargo de trasmitir una noticia insólita, que vivieron poco después personalmente: El Resucitado "se les apareció en el camino, diciéndoles: (Dios os salve); y ellas llegaron y pusiéronse a sus pies y adoráronlo" (EE 301,2). San Jerónimo dice:

"Mujeres fueron las que primero merecieron oír esta palabra 'avete', que quiere decir: Dios os salve; porque la maldición de Eva, que fue la primera mujer, se desatase ya y pereciese en las mujeres. E ellas, recibiendo alegría más que por lengua se puede hablar, allegáronse como personas que ya creían y estaban alumbradas de verdadera fe, según aquello que el Apóstol dice: el que se allega a Dios necesario es que crea, y tuviéronlo y besaron sus pies por devoción, experimentando ser cierta la humanidad en que resucitó, y certificadas de su resurrección adoráronlo como a Dios y como a Señor..." (Cartujano, p. 307).

El Resucitado se presenta así con una humanidad palpable, corporal y a la vez con una teofanía fuera de todo alcance, como Dios y Señor. Y les dice (No temáys; id y decid a mis hermanos que vallan a Galilea, porque alli me verán" (EE 301,3).

De otro lado, el reconocimiento y la adoración de las mujeres ante el Resucitado contrasta con la actitud de Eva, siguiendo la tentación del paraíso, quería ser como Dios y se convirtió en heraldo de seducción y de muerte. Estas se adhieren de lleno al Señor resucitado y por la fe que muestran en su resurrección se convierten en heraldo de una vida nueva.

"Pues mira cómo estas Santas Mujeres hacen aquí oficio de evangelistas, cómo son hechas apostólicas embajadoras de los apóstoles y como van con tanta festinación y diligencia a publicar, como el salmista dice, de mañana la misericordia del Señor... E San Agustin dice: Las mujeres fueron las primeras que hicieron saber a los apóstoles ser Dios resucitado para enmienda de la muerte que Eva administró a su marido, y por esto merecieron ser embajadoras de la salud perdurable a los príncipes de la Iglesia y aunque los apóstoles habían de predicar la resurrección de Cristo a las gentes, las mujeres la predicaron a los apóstoles..." (Cartujano p. 308 s.).

\section{Entre la fe, la duda y el miedo}

El escepticismo de los discípulos no desapareció del todo con el testimonio de las mujeres. A esto se refiere la $4^{\mathrm{a}}$ aparición, tomada de Lucas 24, 9-12; 
33-34 (EE 302). Miedosos y desolados por la muerte de Jesús continuaban los Once en el Cenáculo y les pareció "delirio de mujeres"(Lc 24,9) el mensaje que anunciaba la resurrección, olvidando así o dando por no fidedigno el vaticino de Jesús cuando les aseguró que "el Hijo del hombre había de ser entregado en manos de hombres pecadores y al tercer día resucitar" (Lc 24,6s).

El episodio de los discípulos de Emaus (Lc 24,13-32) se coloca en los Ejercicios como $5^{\mathrm{a}}$ aparición: "Primero: se parece a los discípulos que iban a Emaús hablando de Cristo. $2 .^{\circ}$ : los reprende mostrando por las Escrituras que Cristo había de morir y resucitar: "(;Oh necios y tardos de corazón para creer todo lo que han hablado los profetas! ¿No era necesario que Cristo padeciese $y$ asi entrase en su gloria?) (EE 303). Un Mesías paciente y crucificado era para el judaísmo del tiempo de Jesús, de imposible comprensión. Las muchas tradiciones humanas de escribas y fariseos enrarecían el mensaje de los profetas. Por eso los dos de Emaús habían caído en una gran confusión, iban tristes y frustrados ante lo que había sucedido días antes en Jerusalén.

Mucho les faltaba todavía para alcanzar una fe que asumiera el escándalo de la cruz. Es decir, no creían todavía en Jesús como Hijo de Dios crucificado, sino que esperaban un grande y poderoso profeta, que liberara políticamente a Israel (Lc 24,19-21); por ello, al igual que la Magdalena, aunque Jesús estaba al lado de ellos no lo reconocían. Solo cuando el "forastero" empieza a interpretar las Escrituras, entonces se les comienza a aclarar el sentido de lo ocurrido. De poco sirve conocer al Jesús terreno y la historia de Israel o la sorprendente noticia de las mujeres acerca del sepulcro vacío, es preciso ante todo escuchar las Escrituras, interpretadas por Cristo, que fue lo que les hizo "arder el corazón", pero el total reconocimiento no se realiza sino durante la fracción del pan, en la Eucaristía.

El Mesías aparece en la Biblia con diversas connotaciones ${ }^{12}$. La figura del "justo sufriente" da su vida en sacrificio (Is 53,10) y de esta forma obtiene la justificación para la muchedumbre (Is 53,11) y una asombrosa glorificación. Los dos de Emaús pensaban, como ya se indicó, en un mesianismo muy distinto. El "forastero" los escucha, pero ve que están equivocados. Tanto tiem-

${ }^{12}$ Dios quiere salvar a su pueblo, y para ello se sirve de intermediarios, que son ante todo reyes ungidos, "mesías" a quienes se les confía la misión de promover los planes de Iahvé: realizar su reino, que coincide con la subida al trono de David. El Sal 72 es un verdadero salmo mesiánico. Subraya que el deber del rey-mesías es el ejercicio de la justicia. De esta forma el mesías-rey comienza a ser cada vez más idealizado. El primer oráculo de Isaías (7,10-14) consiste en el nacimiento de un niño misterioso llamado "Emanuel", como expresión de la presencia divina en la historia de Israel. La larga serie de figuras bíblicas del "justo doliente" alcanza su cima en Is 53,10. Cf. "Mesianismo" en: P. Rossano / G. Ravasi / A. Girlanda (directores) Nuevo Diccionario de Teología Bíblica,, Madrid 1990, 1170 ss. 
po, al parecer, con Jesús y todavía no habían entendido una de las cosas más decisivas de su persona y mensaje. El Cartujano remarca: "Mira cómo estos dos discípulos manifiestan ser nuestro Redentor profeta, mas no confesaban que era Hijo de Dios, en lo cual parece que aún no creían del todo [...]. Y decían esto como personas que tenían ya muy adelgazada toda su esperanza acerca de la resurrección del Redentor" (p.315).

En esta aparición se entrevé bien la profunda crisis que, por causa del trágico final, se había apoderado de los que seguían a Jesús. La condena a muerte y la crucifisión habían roto las esperanzas de liberación mesiánica nacional-judía. En esta situación la palabra de Jesús, apelando a las profecías de la Escritura (Lc 24,27), hace renacer la esperanza. Su pasión y muerte no contradicen el designio salvífico de Dios, sino que lo llevan a su cumplimiento. La resurrección no significa sólo dar sentido a los sufrimientos de Cristo, sino que forma parte de su misión junto con la muerte, como dos fases de una misma finalidad. "¿No era necesario que el Mesías padeciera y entrara en su gloria?". En estas palabras, muerte y resurrección no se yuxtaponen, se coordinan. La muerte es condición previa para la gloria; dicho de otro modo: la glorificación del Crucificado constituye el comienzo del Reino que él había anunciado desde un principio (Mc 1,15).

Los de Emaus cambian de dirección y vuelven llenos de alegría a Jerusalén, donde encuentran a los Once. Las visitas al sepulcro, las desconcertantes noticias de la tumba vacía, todo ello había originado división de opiniones: algunos favorables al hecho de la resurrección, otros escépticos. Una resurrección apoteósica, manifiesta a los ojos de la gente ciertamente que no se había producido. Además, ¿por qué primero se aparece a las mujeres y no a los apóstoles? Simón Pedro había salido con Juan, aquella mañana, a verificar lo que decía la Magdalena. Los dos discípulos corrieron al sepulcro; llegó primero el discípulo preferido de Jesús, pero no entró hasta que llegó Pedro, que entró y vio los lienzos por el suelo, el sudario con que habían envuelto la cabeza no estaba en el suelo con los lienzos, sino doblado en un lugar aparte. Entonces entró el otro discípulo que había llegado antes, vio y creyó (Jn 20,3-8). Tal vez Pedro, pensando en la experiencia del Monte Tabor con la Transfiguración de Jesús en tanta gloria, se esperaba más que un simple sepulcro vacío.

Pero más tarde, pensando en lo que decía la Magdalena, a Pedro debió de pesarle el no haber esperado ante el sepulcro, como lo hicieron las mujeres, tal vez se le hubiese aparecido en compañía de ellas. Por ello, es de suponer que Pedro fue otra vez al sepulcro: "pensando San Pedro en estas cosas se le apareció Cristo, y por eso los discípulos decían: (Verdaderamente el Señor ha resucitado y aparecido a Simón) (EE 302,3). Esta afirmación califica a Pedro 
como testigo autorizado de la resurrección ${ }^{13}$. En esto llegan los dos de Emaús, refiriendo su experiencia. Con todo, algunos de los discípulos todavía se resistían a creer. Tampoco el miedo a ser perseguidos, había desaparecido, como se resalta la 6. a aparición, tomada de Jn 20,19-23: "Primero: Los discípulos estaban congregados (por el miedo a los judios), excepto Tomás" (EE 304).

Mucho temor debieron aún tener cuando incluso cerraron las puertas de la casa, pensando tal vez que una cohorte de soldados podría venir para someterlos a juicio, como hicieron con el Maestro. Pero he aquí, que, "se les apareció Jesús estando las puertas cerradas" (EE 304,2). Esta forma de aparecerse, traspasando cuerpos opacos, le asemejaba o hacía pensar en un ser incorpóreo, algo aparente, no real o un fantasma. A. Orbe observa que esta aparición se utilizó después para negar no solo la realidad de la resurrección corporal de Cristo, sino también la de la encarnación. Si Jesús fue incorpóreo, no sufrió los dolores de la pasión y muerte, luego tampoco la "kénosis" fue auténtica ni, por tanto, la salvación; fue solo algo metafí$\operatorname{sico}^{14}$. Estas ideas pueden estar relacionadas con el dualismo helénico que separa ánima y cuerpo y desemboca a veces en un espiritualismo gnóstico che desprecia lo que sea corporal o material ${ }^{15}$.

Los escritos del NT concuerdan, por el contrario, en situar el origen de la acción salvífica de Cristo en aquello que realizó en su humanidad corporal y que se sintetiza en la palabra "encarnación", que muestra hasta qué punto la Carne o el Cuerpo es el ámbito en que se decide sobre la salvación del ser humano. En 1Cor 15,46 Pablo utiliza la expresión "cuerpo espiritual"; efectivamente, la corporeidad del Resucitado es pneumática, no porque sea algo etéreo, irreal o especulativo, sino porque está anclada y animada por la fuerza del Espíritu Santo. Partiendo de la comparación con la semilla arrojada en la tierra que tiene que morir para dar nueva vida (1Cor 43), Pablo explica cómo

${ }^{13}$ El Cartujano resalta la importancia de esta aparición por diversas razones: "La primera, porque San Pedro fue el primero que confesó ser Cristo Dios y hombre, y de esta causa era razón que mereciese él ver primero que los otros apóstoles la resurrección. La segunda, porque reformase y alumbrase la fe de su entendimiento que se había enflaquecido como edificio movedizo en la pasión, porque aquel que de temor de su pasión cruel más de manifiesto había caído, se levantase primero considerando en su maestro la verdad y la hermosura de su resurrección. La tercera, por le manifestar que le eran perdonado el pecado de la trina negación, consolándolo, porque no desesperase. La cuarta es, por fortificar, apareciéndole a él primero que a todos..." 311

${ }^{14}$ A. Orbe, op. cit. 197.

${ }^{15}$ El cuerpo estaba considerado como una tumba o una cárcel para el alma; y la muerte, en cuanto separación del alma del cuerpo, como una liberación al que lógicamente no deseaba volver. 
Dios es capaz de recrear los cuerpos corruptibles en cuerpos incorruptibles: "Y cuando este cuerpo corruptible se revista de incorruptibilidad y este cuerpo mortal se revista de inmortalidad, entonces se realizará la palabra que está escrita: 'Devorada ha sido la muerte para siempre' ‘Dónde está, oh muerte, tu victoria? ¿Dónde está, oh muerte, tu aguijón?’”(1Cor 15,54-55).

El cuerpo del Resucitado no es un cuerpo reanimado como el de Lázaro; el cuerpo de Jesús es un cuerpo trasformado, de cuya posibilidad dio muestras la transfiguración: "su cara resplandecía como el sol y sus vestiduras como la nieve"(EE 284), pero no por ello cambia su identidad: sigue siendo la misma persona de antes. Cristo resucitado manifiesta la plenitud de su condición divina, "escondida" durante su vida terrena, sobre todo durante la pasión y muerte: "considerar cómo la Divinidad, que parecía esconderse en la pasión, parece y se muestra agora tan miraculosamente en la santísima resurrección" (EE 223).

"Y estando en medio de ellos dice: (Paz con vosotros)" (EE 304,2). Saludar de este modo es lo normal y corriente entre judíos. Aquí es mucho más, hace recordar lo dicho en el discurso de despedida: "La paz os dejo mi paz os doy (Jn 14,27). El sosiego y la soberana paz del Señor contrasta con la turbación y la inseguridad de los discípulos. Jesús los tranquiliza ante su inesperada aparición y ante el miedo que tenían a los judíos. En cambio entre personas de fe sincera la aparición habría producido, como en el caso de su Madre y de la Magdalena, un alegría indecible y una gran consolación.

Jesús, constatando que los discípulos no estaban todavía muy convencidos, los invita a comprobar su realidad corporal. "Creían estar viendo un espíritu". Él les muestra, en cambio, sus manos y sus pies; "palpad y ved", "porque un espíritu no tiene carne y huesos", y también les señala las llagas de los clavos y el costado herido con la lanza para que vean que el Resucitado no es otro que el Jesús crucificado, aunque con una existencia totalmente diferente a la terrena, ya que ahora está plenamente poseído por el poder divino del Pneuma en su humanidad, a fin de poder comunicarlo a los demás: "3.”. dales el Espíritu Santo diciéndoles: (Recibid el Espiritu Santo: a aquellos que perdonáredes los pecados, les serán perdonados” (EE 304). A este respecto A. Orbe resalta: "No está la mediación de Jesús en solo el Verbo. Está en el Verbo Encarnado. Ni siquiera en solo el Verbo hecho carne, sino en el Verbo glorificado (o deificado) en carne. El vehículo por el que el Hijo de Dios derrama el Espíritu sobre sus hermanos es su Cuerpo clarificado" ${ }^{16}$.

Jesús pidió a la Magdalena que avisara a sus hermanos de que subía al Padre; ahora les comunica el fruto de ese retorno al Padre, el Espíritu Santo. La

\footnotetext{
${ }^{16}$ A. Orbe, op. cit. 204s.
} 
misión de perdonar no deriva, pues, principalmente de una palabra de Jesús, sino que procede de la relación que une a Jesús con su Padre. Jesús aparece como el representante que revela el Padre al mundo, y, por tanto, la misión confiada a los discípulos prolonga la misión del Padre a Jesús: "Como el Padre me ha enviado también yo os envió"(Jn 20,21). Por esto, en la perspectiva de Juan ha llegado la hora de dar el Pneuma de la verdad, "que yo os enviaré de junto al Padre" (Jn 15,26). Así se cumple lo anunciado en el discurso de despedida. En el Cartujano se dice:

"Nota que por manera de flato o de viento dio nuestro Redentor a los discípulos el Espíritu Santo, por mostrar que él mesmo era el que en la faz del hombre primero espiró el espiráculo del ánima intelectiva y racional, que es forma natural y viva del cuerpo humano; y también les dio el Espíritu Santo en esta manera, por mostrar que el mesmo Espíritu Santo igualmente procede de él ansí come procede del Padre” (p. 323).

Como el Verbo divino en el momento de la creación espiró al hombre la vida racional, ahora el Verbo eterno encarnado y glorificado trasmite a la humanidad la vida del Padre por el Pneuma . Es la versión joánica de la Pentecostés, que Lucas colocará cincuenta días después del domingo de resurrección; no como un evento separado de la Pascua sino como su complemento y culminación ${ }^{17}$.

La 7. a aparición tiene como protagonista a Tomás, "incrédulo, porque era absente de la aparición precedente, dice: (Si no lo viere, no lo creeré)" (EE $305,1)$. Esta era su respuesta a las muchas cosas que le contaban de haber visto a Jesús resucitado, su cuerpo con las marcas de los clavos y con el costado abierto. Cuando se ausentó estaban tristes y atemorizados, y ahora los encuentra desbordantes de alegría; pero Tomás seguía negando; no entendía la realidad de la fe pura: creer sin haber visto, sin experiencia propia, confiando solo en la palabra del que ha visto, del testimonio. Debía creer partiendo del misterio que sus hermanos de alguna manera habían experimentado. En esto "se les aparece Jesús desde ahí a ocho días, estando cerradas las puertas, y dice a Santo Tomás: (Mete aqui tu dedo, y ve la verdad, y no quieras ser incrédulo, sino fiel) (EE 305,2).

Al meter su dedo y su mano en las llagas del Resucitado venció sus dudas: "Santo Tomás creyó, diciendo: (Señor mío y Dios mío)"(EE 305,3). La Magdalena exclamó, al reconocer al Resucitado: "Rabboni". A la palabra siguió el gesto de echarse a sus pies para adorarlo. De modo semejante, Tomás trasmite

${ }^{17} \mathrm{El}$ encuentro con Cristo resucitado es ya desde un principio una experiencia pentecostal. Cf. F. X. Durrwell, Jesus Fils de Dieu dans l'Esprit Saint, París 1997. Para la pneumatología de los Ejercicios cf. R. García Mateo, Ignacio de Loyola. Su espiritualidad y su mundo cultural, Bilbao 2000, 353-371. 
a los creyentes en Cristo una expresión muy feliz para confesarlo. El Cartujano lo comenta:

"no sólo creyendo con el corazón, mas aun confesando la fe con la boca, ca lo uno y lo otro se requieren para la salud del ánima, y dijo con devota exclamación: Verdaderamente eres Señor mío y Dios mío. Señor, según la humanidad en la cual me redimiste y compraste con tu sangre; Dios mío, según la divinidad por la cual me criaste y me formaste de la tierra. Ya ninguna cosa dudo, certificado estoy de tu fe. Yo, Señor, confirmo tu resurrección y yo predico la inmortalidad..." (p. 325)

Que Jesús sea llamado Señor no resulta extraño; es uno de los primeros títulos que recibe el Resucitado (He 2,36; Fil 2,11). La novedad de la confesión tomasiana es que lo califique de Dios. Es uno de los pocos textos del NT que afirma la divinidad de Jesús con tanta claridad, si bien es verdad que sería exagerado pensar que Tomás de este modo expresara una afirmación dogmática, como hará, siglos después, el concilio de Calcedonia. Lo que sí es cierto es que en el conjunto del cuarto evangelio hay que honrar al Hijo como se honra al Padre (Jn 5,23). Y Jesús ha dicho: "Yo y el Padre somos uno" (Jn 10,30).

Tomás ha alcanzado la fe en el Resucitado, pero ello no quiere decir que la fe dependa necesariamente de ciertas apariciones o visiones, por eso Cristo responde a Tomás, diciendo: "(Bienaventurados son los que no vieron y creyeron)" . Sin embargo, esta respuesta tampoco subestima la experiencia de la visión, sino que sitúa en el mismo nivel a los creyentes que han tenido la experiencia del Cristo glorioso y a los que creerán después por el testimonio de ellos. Teniendo en cuenta los futuros creyentes, que se encontrarán en una situación muy distinta a la de Tomás y los demás discípulos, se alaba la fe sin "apariciones", la fe pura. La carta a los Hebreos da de la fe una noción que después ha sido elaborada por la teología: "La fe es la firme seguridad de lo que esperamos, la convicción de lo que no vemos" $(11.1)^{18}$. Da, pues, la esperanza de que se alcanzarán las promesas reveladas, pese a toda contrariedad, tal fue el caso de Abraham y de María.

La octava aparición está tomada de Jn 21, 1-17 (EE 306): "Primero: Jesús aparece a siete de sus discípulos que estaban pescando, los cuales por toda la noche no habían tomado nada". Había sido una iniciativa de Pedro. Se sentían gozosos, porque sabían que el Maestro estaba vivo, pero ignoraban las circunstancias de su futuro. No acababan de coordinar su origen judío con la novedad del mensaje de Jesús, de manera que sus ideas resultaban todavía bastante confusas. Ya de mañana, se presenta el Resucitado en la ribera del lago, pero los discípulos no lo reconocen. Se presentó sin ángeles, sin poderes

\footnotetext{
${ }^{18}$ Catecismo de la Iglesia Católica, n. 150ss.
} 
divinos, como aquellos de dominar los vientos y los mares caminando sobre las aguas (EE 279-280). Jesús inicia desde la orilla un diálogo; a los de Emaús se les asoció, como un caminante más; a la Magdalena, como un hortelano, y ahora entra en contacto con estos discípulos preguntándoles si tienen algo para comer; pero no habían pescado nada durante toda la noche. Entonces Jesús les dice que echaran la red a la derecha de la barca (Jn 21,6), "y extendiendo la red por su mandamiento (no podían sacarla por la muchedumbre de peces)".

Hubo dos pescas, una antes y otra después de la resurrección. En la primera, Jesús ruega a Pedro de remar mar adentro y soltar las redes para la pesca. A lo que Pedro respondió que toda la noche habían estado faenando pero que nada habían cogido, "mas en tu nombre echaré las redes" (Lc 5,5-6). Cayó mucha cantidad de peces. Pedro y los demás discípulos se llenaron de estupor. Desde ahora, les dijo, "os haré pescadores de hombres" (Mt 4,19) ${ }^{19}$ En la pesca después de la resurrección, observamos que, a diferencia de la primera, se indica que se "echen las redes a la derecha". Jesús había dicho que en el juicio final pondría los malos a la izquierda y los buenos a la derecha (Mt 25,41).

La pesca es en los evangelios desde el principio más que un oficio una imagen para describir la vocación esencialmente apostólica de los discípulos. Desde la barca se arroja la amplia red, que tiene la misión de recoger a cuantos quieran incorporarse a la fe en Cristo. En la ausencia de él, los discípulos, expertos profesionales de la pesca, son incapaces, sin embargo, de conseguir pez alguno. Sólo en nombre de Jesús, incluso contra todos los pronósticos, será posible el éxito pastoral. El Cartujano comenta:

"Porque estos siete pescadores que son aquí contados, es figurada la universidad de los predicadores de la Iglesia, que sin la virtud de Jesucristo ningún corazón prende en la red de sus predicaciones y ninguna cosa pueden aprovechar, porque sin disciplina y alumbramiento interior en vano trabaja la lengua del predicador, mas cuando en la mañana viene la luz alumbradora de los corazones, obrándolo, como principal causa, nuestro Redentor Cristo, pescan copiosa de peces, por la cual es figurada la multitud de los que habían de creer por la predicación de los apóstoles" (p.326).

Ni la presencia de Jesús a la orilla del lago ni su palabra permite identificarle, de momento, pero "por este milagro San Joán lo conoció, y dijo a San Pedro: (El Señor es), el cual se echó en la mar y vino a Cristo" (EE 306,2). Fue el discípulo predilecto el primero que reconoció a Jesús resucitado des-

${ }^{19}$ El Cartujano añade: "Item en aquella pesca primera dice el evangelista que se rompía la red con el mucho pescado, significando en la rotura los cismas y divisiones y turbaciones que muchas veces ha habido y hay, y las que antes de la fin del mundo habrá en el estado de la Iglesia presente; mas en este pescar de agora no se rompió la red, por significar que en aquella soberana paz de los santos ningunos cismas habrá ni divisiones..." (p. 329). 
pués de la pesca milagrosa, como también fue el primero que creyó en su resurrección al ver la tumba vacía (Jn 20,8). Todo ello lo convierte en ejemplo del verdadero creyente. Pero es Pedro, quien por su prontitud arrojadiza primero va al encuentro del Señor; se echó al agua y nadó hasta encontrar a Jesús en la orilla. Los demás vienen en la barca, y arrastran la red llena de peces.

Tras una noche de pesca, seguro que se tiene hambre. Jesús les preparó un pez asado y un pan. Los Ejercicios dicen: "les dio a comer parte de un pez asado y un panal de miel" (306,3). En apariencia, un modesto desayuno; simbólicamente, muy alto. Jesús había multiplicado panes y peces para saciar el hambre, pero sobre todo para dar a pregustar su cualidad de ser "pan de vida eterna" (Jn 6,35). Como en el relato de Emaús, aquí se invita a vivir el encuentro del Resucitado en la comunión eucarística.

Después de la parva colación, se produjo un diálogo, en el que Jesús "encomendó las ovejas a San Pedro, primero examinado tres veces de la caridad, y le dice: (Apacienta mis ovejas)" (EE 306,3). Efectivamente, las tres preguntas que Jesús dirige a Pedro no son simplemente una réplica a las tres negaciones durante el proceso que condenó Jesús a muerte, sino que responden a un verdadero examen o discernimiento sobre el modo en que se ama. En griego se distinguen, como es sabido, tres formas de amar: eros, filia, ágape. Eros expresa el amor egocéntrico, que quiere poseer al otro; con filia se denomina el amor de amistad, que comparte con el otro, mientras que ágape significa el amor-servicio al otro.

Leyendo el original griego de este texto (Jn 21,1-14), se observa que la primera vez que Jesús pregunta a Pedro si lo ama, lo hace con ágape, o sea, demandando un amor incondicional. Pedro, examinando su relación con Jesús, reconoce que su amor a Cristo a veces no ha sido total e incondicional, sino infiel y oportunista, llegando incluso a negar que lo conocía, por ello no puede responder con ágape, dice simplemente: "Señor, te quiero (filô-se)", es decir, "te amo con mi frágil amor humano". Cristo de nuevo insiste con ágape: "Simón, me amas totalmente?". Pedro, sin embargo, repite la respuesta de su pobre amor: "Señor, te quiero con mis limitaciones". La tercera vez, Jesús omite, como en la segunda, la comparación: "me amas más que estos", y no hace la pregunta con ágape, sino con filia: “¿Simón fileîs-me?” Pedro sintió de este modo una gran pena por la fragilidad de su amor y, al mismo tiempo, el convencimiento de que solo Jesús conoce, de verdad la realidad de su amor: "Señor, tú lo sabes todo; tu bien sabes que te amo", o sea, el siente que su amor a Jesús es insuficiente e indigno, pero por su experiencia sabe que no puede prometer más. El Cartujano, citando a Crisóstomo, comenta:

"De nuevo tornó a temer San Pedro que por ventura, pensando él amar mucho a Jesucristo, no sea corregido si desde allí adelante no lo amare como 
fue primero reprendido cuando pensaba estar muy fuerte y más forzado para morir por él que todos sus hermanos, y por eso a este mismo Cristo recurre y comete la verdad de esta pregunta y le dice: Señor, tu sabes todas las cosas y todos conceptos invisibles del corazón y todos los hechos presentes y todos los acabamientos que están por venir. Y así del profundo del corazón respondió esta voz de verdadero amador: Tú,Señor, sabes que te amo..." (p. 330s).

Jesús le responde de nuevo: Apacienta mis ovejas. Como si dijera: No por haberme negado tres veces, retiro mis promesas. Pese a la fragilidad de tu amor, te constituyo en Pastor de mi Iglesia. El Padre y yo, unidos en ti por el Espíritu, inmutables en la elección lo seremos también en la ayuda. Las ovejas no cambian de dueño. Siguen siendo de Cristo, no de Pedro; de aquí que no se deba buscar el amor de ellas. Jesús amó a su Iglesia por encima del desamor de esta, lo mismo debe hacer Pedro.

\section{Misión y Ascensión, la experiencia paulina}

En la novena aparición (EE 307), que se refiere a Mt 28,16-18, no hallamos, a diferencia de las anteriores, una presencia inesperada del Resucitado, ya que él mismo había convocado a los discípulos a venir al monte de la Galilea (Mt 26,32; 28,7), ni tampoco la experiencia de haber sido reconocido, sin embargo, la mission, que en las otras apariciones constituye el tercer elemento, aquí es claramente lo esencial, adquiere un relieve extraordinario: "Cristo se les aparece y dice: (Dada me es toda potestad en cielo y en tierra)" (EE 307,2). Jesús mismo, durante su proceso, cuando le preguntaron "¿Eres tú el Mesías, el Hijo de Dios?", afirmó: "Tú lo has dicho; y vosotros mismos veréis que el Hijo del hombre estará sentado a la diestra del Poder como lugarteniente de Dios" (Mt 26, 64). Jesús resucitado está investido de poderes mesiánicos y puesto al frente de una nueva humanidad. La piedra rechazada en la pasión, deviene piedra angular. La resurrección no es solo una prueba de la promesa mesiánica, es su realización. La concesión de "toda potestad" está, pues, implícita en la misma resurrección. Por ello puede enviar con plena autoridad, "diciendo: (Id y enseñar todas las gentes, bautizándolas en nombre del Padre y del Hijo y del Espíritu Santo) (EE 307,3).

La misión que ahora se encomienda es distinta de aquella realizada durante la vida terrestre de Jesús, destinada a solo los judíos (Mt 10,5-6); esta, sin embargo, va dirigida a "todas las gentes", a todos los pueblos. Tampoco se trata de breves encuentros con el Resucitado en el trascurso de los cuales Jesús se hace reconocer familiarmente y confiere una misión, sin apariencia de autoridad. En esta, por el contrario, se trata de una proclamación solemne del 
poder supremo que se le ha concedido, en virtud del cual puede enviar a sus discípulos a una empresa de dimensiones universales como a legados suyos.

"E dijo esto porque aunque, en cuanto a la divinidad siempre estuviese tenido este poder eterno y también lo tenía en cuanto hombre desde el punto que fue concebido en el vientre virginal, por verdadera autoridad, empero no lo tuvo ejecutivamente y para usar siempre de él, hasta que resucitase de los muertos, mas antes quiso ser sujeto a penosa pasividad por obrar nuestra redención" (Cartujano, p. 333).

Claro, que Cristo, en cuanto segunda Persona del Dios trino, tiene los poderes divinos desde toda la eternidad, pero aquí habla como "Verbo eterno encarnado" (EE 109), como Salvador, que, ha llevado a cabo su obra redentora, venciendo los poderes del pecado, del mal y de la muerte; tiene, pues, pleno derecho a congregar a todos en el "Reino" que él predicó, testimonió en su persona y manifestó con sus milagros, y que ahora, con su muerte y resurrección, se hace realidad en la tierra y llegará a su plenitud escatológica. Pero para entrar en él es preciso renacer del agua y del Espíritu, que brotan de su cuerpo glorioso (Jn 7, 37-39; ). De este modo la misión apostólica se origina y desarrolla a través de la mediación histórica de Jesús, pero desde la dinámica misional del Dios trinitario. En el Diario espiritual de Ignacio se dice, al tratar el modo de vivir la pobreza evangélica en la Compañía que "el Hijo envió en pobreza a los apóstoles, y después el Espíritu, dando su Espíritu y lenguas los confirmó, y así el Padre y el Hijo, enviando el Espíritu Santo, todas tres personas confirmaron la tal misión" $([15])^{20}$.

Comparando esta aparición con las anteriores, se pregunta la exegesis ¿hasta qué punto esta se diferencia de las demás? ${ }^{21}$ Ella recapitula y da un significado unitivo a las otras, como punto culminante; este es también el sentido que se descubre en el hecho de que Ignacio la haya puesto al final de las apariciones evangélicas, como asimismo sucede, en el "Vita Christi Cartujano", enlazando directamente con la Ascensión, cuya temática está ya presente en esta aparición.

Hemos visto que la iniciativa es del Resucitado. Él, aunque de forma velada, es el que sale al encuentro, dejándose ver, bendiciendo, consolando, enviando, manifestando poderes divinos; en otras ocasiones, se come con él, como si fuese un ser como los demás mortales. Con ello se quiere resaltar que, pese a toda diferencia, la continuidad entre el Crucificado y el Resucitado es real; no es algo insólito o fantasmagórico. A este respecto Benedicto XVI

${ }^{20}$ R. GARCía MATEO, “«Criador y Redentor nuestro». La misión del Hijo según Ignacio de Loyola”: Estudios Eclesiásticos 90 (2015) 569-591.

${ }^{21}$ X. LÉon-Dufour, Resurrección de Jesús y mensaje pascual, Salamanca 1974, Sígueme, 154. 
subraya: "La paradoja era indescriptible: por un lado, Él era completamente diferente, no un cadáver reanimado, sino alguien que vivía desde Dios de un modo nuevo y para siempre; y, al mismo tiempo, precisamente Él, aun sin pertenecer ya a nuestro mundo, estaba presente de manera real, en su plena identidad"22.

De aquí se desprende la estrecha correlación entre cruz, resurrección, exaltación y envío del Espíritu. Viernes Santo, Domingo de Resurrección, Ascensión y Pentecostés forman, como se sabe, un único e indivisible misterio pascual; en consecuencia, la resurrección de Cristo es ya su ascensión a la diestra del Padre en la fuerza del Espíritu, con plenitud de poder sobre el cielo y la tierra (1Cor 15,35-49; Rm 1,4).

Sin embargo, respecto a los discípulos, la profundidad y riqueza del misterio pascual no se pudo y no se puede percibir de una vez por todas. Se necesita de largo tiempo de meditación y contemplación para llegar a una cierta comprensión de estos misterios, como ya han mostrado los relatos de las apariciones. Lucas, con más sentido pedagógico, intercala un periodo de 40 días que sirven, a su vez, para celebrar litúrgicamente la presencia del Cristo glorioso como tiempo pascual.

El relato lucano de la ascensión, Hech 1,1-12, es el texto que utilizan los Ejercicios para contemplar este misterio (EE 312): "Primero: después que por espacio de cuarenta días apareció a los apóstoles, haciendo muchos argumentos y señales y hablando del reino de Dios..." Así se afirma cómo con la resurrección de Cristo viene el reino que él anunciaba, algo que la teología de hoy subraya: "El encuentro con el Señor resucitado se califica en el NT como encuentro y experiencia de Dios. Lo que los discípulos vieron fue la realidad del reino de Dios, llegado definitivamente en Jesucristo mediante su muerte, percibieron el resplandor de la gloria de Dios en el rostro del Crucificado"23.

Sin embargo y pese a los 40 días, en los que Jesús estuvo mostrándoles qué es el reino de Dios que él predicó y personifica no como una estructura político-social de Israel, sino como presencia universal del amor divino escatológico, con todo, surge entre los discípulos, poco antes de la partida ascensional, la cuestión judaica: "¿Señor, es este el momento en que vas a restaurar el reino de Israel?"(He 1,6). A. Orbe con bastante indignación afirma:

"El amor de Jesús no conoce penitencia. Disimula. Escucha la disparatada salida de los Once. 'No os toca a vosotros - les decía - conocer los tiempos y momentos oportunos que el Padre fijó con su poder' [...]. Llegarán tiempos y

22 J. Ratzinger-Benedicto XVI, Jesús de Nazaret. Desde la entrada en Jerusalén hasta la Resurrección, Madrid 2011, 286s.

${ }^{23}$ W. KASPER, op. cit., $173 \mathrm{~s}$. 
momentos en que, iluminados por el Espíritu común al Padre y al Hijo, entren en el misterio de la Dispensación" ${ }^{24}$. En este sentido los Ejercicios afirman:

"...mandóles que en Jerusalén esperasen el Espíritu Santo prometido" (EE 312,1).

En efecto, como se está comprobando, muchas cosas de la fe no las captaron correctamente, necesitaban de más conocimiento, de un magisterio "particular", que les enseñara "toda la verdad" y se convencieran que el verdadero Mesías no se sentará sobre el trono de David, sino sobre el trono de Dios (Mt $22,41-45)$. Por ello Jesús ya les prometió que les enviaría "otro Consolador"; de aquí que su despedida no sea una ausencia completa, solo de vista, no de presencia, ya que el otro Consolador no es otro que su propio Espíritu, hasta el punto que su actividad pascual se caracteriza por "el oficio de consolar"(EE 224). Pero el consolar del Resucitado es distinto al del Paráclito. Cristo consuela de modo semejante a "cómo unos amigos suelen consolar a otros", en forma de encuentro, de conversación, como se ha mostrado en las apariciones; mientras que el Espíritu consuela consolando, haciendo posible que la consolación del Padre mediante el Hijo llegue al creyente.

Era, por tano, de suma conveniencia que la humanidad de Cristo, glorificada de lleno por el Padre, iniciase la efusión del Espíritu mesiánico. El AT, debido a la infidelidad de Israel a la alianza divina, lo venía prometiendo desde hacía tiempo: "Y después de esto infundiré mi espíritu en toda carne, y profetizarán vuestros hijos e hijas; vuestros ancianos soñarán sueños, vuestros jóvenes verán visiones. E incluso sobre los siervos y las siervas por aquellos días infundiré mi Espíritu"(Joel 2,18s). Este texto lo citará Pedro en el discurso del día de Pentecostés (Hech 2,17s), para proclamar que tal abundancia y variedad de carismas son manifestación de que la Nueva Alianza, que Jesús ha hecho posible con su obra redentora, se hace realidad con la efusión de su Espíritu.

Diversos hechos y experiencias se asocian en torno a la Ascensión: "2.": sacólos al monte Olivete (y en presencia de ellos fue elevado y una nube le hizo desaparecer de los ojos de ellos) (EE 312). Entre los significados que la nube puede tener, destaca el que la interpreta como símbolo de la exuberancia de dones del Espíritu que serán comunicados a la humanidad. En el monte de la Transfiguración (EE 284) ocurrió algo parecido. Una nube cubrió a Jesús, Pedro, Santiago y Juan (Mt 17,5), a la manera de las teofanías del AT, y se oyó la voz del Padre, que daba testimonio del Hijo; ahora son mensajeros divinos, los encargados de atestiguar: "mirando ellos al cielo les dicen los ángeles: (Varones galileos, ¿a qué estáis mirando al

${ }^{24}$ A. Orbe, op. cit., 327. 
cielo?; este Jesús, el cual es llevado de vuestros ojos al cielo, así vendrá como le visteis ir en el cielo" (EE 312,3).

La mirada fija duró poco, la visión beatifica será después de la muerte. Ahora hasta los seres celestiales invitan a mirar a la tierra, a ir por el mundo, entre las gentes anunciando, testimoniando el Reino de justicia de amor y de paz que Cristo hace posible. Su desaparición mediante la nube no es obviamente la de una subida a las estrellas, sino la de un entrar definitivo en el "Reino de los cielos", en la trascendencia del Amor divino, para "sentarse a la derecha de Dios Padre". Sentarse uno al lado de otro, a su diestra, significa, según la mentalidad bíblica, igualársele en dignidad y poder. El que, como Verbo eterno del Padre es desde siempre igual a Dios, se hizo carne ("sarx") hasta la muerte de cruz, y con la Resurrección-Ascensión, Dios ha glorificado su realidad humana, de modo que "la Divinidad, que parecía esconderse en la pasión, parece y se muestra agora tan miraculosamente en la santísima resurrección, por los verdaderos y santísimos efectos de ella" (EE 223): "ha sido exaltado sobremanera y se le otorga aquel nombre que es sobre todo nombre. A fin de que al nombre de Jesús se doble toda rodilla: de los seres celestes, de los terrenos y de los infernales. Y que toda lengua proclame que Jesucristo es el Señor en la gloria de Dios Padre" (Fil 2,9-11). A este efecto cósmico corresponde la figura del "Rey eternal" que se presentaba al principio de la Segunda Semana:

"ver a Cristo nuestro Señor, rey eterno, y delante de él todo el universo mundo, al cual y a cada uno en particular llama y dice: Mi voluntad es de conquistar todo el mundo y todos los enemigos y así entrar en la gloria de mi Padre; por tanto, quien quisiere venir conmigo ha de trabajar conmigo, porque siguiéndome en la pena, también me siga en la gloria" (EE 95, 1).

Así se expresa cómo esta meditación pone el marco cristológico fundamental de los Ejercicios y se clarifica cómo a la Resurrección-Ascensión subyace el misterio trinitario; es obra del Padre, cuyo poder "ha resucitado" a Cristo (He 2,24) y de esta manera se ha incorporado la humanidad del Hijo en la comunión trinitaria (Rm 6,4; Fil 3,10) mediante la acción del Pneuma que ha vivificado la humanidad muerta de Jesús.

En cuanto al Hijo, él no es solo objeto della Resurrección, sino que participa en ella activamente: "Doy mi vida, para recobrarla de nuevo... Tengo poder para darla y recobrarla otra vez"(Jn 10, 17-18). Está plenamente dotado para infundir el Espíritu del Padre; es el perfecto Mediador para deificar a toda la humanidad con la fuerza del Paráclito, y de esta manera que las peticiones de "Venga tu Reino" y "Hágase tu voluntad" sean cada vez más escuchadas , hasta que llegue el día de su venida final: "así vendrá como le visteis ir en el cielo". Su partida es, como ya se indicó, no una ausencia total, sino una nueva 
forma de cercanía. Estando junto a Dios, está en todo lugar y en todo tiempo, en particular en su Iglesia y en sus sacramentos. Desde el marco trinitario se contempla mejor la dimensión universal y cósmica que adquiere Jesús con su Resurrección-Ascensión, así como su función respecto a la Iglesia y a la humanidad entera. La aparición a Pablo tiene ya el contexto pos-ascensional. En 1Cor 15,3-9 Pablo, enumerando los testimonios de la resurrección, afirma:

"Os trasmití, en primer lugar, lo que a mi vez recibí: que Cristo murió por nuestros pecados - según las Escrituras, que fue sepultado, que resucitó - el tercer día - según las Escrituras, que se hizo ver de Cefas, y luego a los doce, después se apareció a más quinientos hermanos de una vez, de los cuales viven todavía; algunos pocos ya murieron. Se apareció también a Santiago, luego a todos los apóstoles. Y a lo último, después de todos, como un abortivo, se me apareció también a mí. Pues yo soy el ínfimo de los apóstoles, ya que perseguí a la Iglesia de Dios".

Según Lucas las apariciones fueron un privilegio de la generación apostólica y cesaron a los 40 días de la resurrección. Esta afirmación es solo valida si se tiene en cuenta el contenido simbólico del número 40; Pablo, por el contrario, es de la opinión que la aparición que él ha tenido es de la misma naturaleza y del mismo alcance que las de los Once. La lista que él enumera desborda el esquema lucano, presentando las apariciones no simplemente como algo exclusivo de los primeros discípulos, sino igualmente como prototipo de la relación del Resucitado con los creyentes de todos los tiempos en Cristo.

A diferencia de los relatos de las apariciones evangélicas, que fueron redactados por narradores que los oyeron contar, el relato de Pablo es el único testigo que ha hablado personalmente de ello y está considerado por la exegesis como el texto históricamente más importante de todos los que se conocen. En los Ejercicios este pasaje constituye el marco de las tres últimas apariciones (EE 308, 309, 311). A la lista de los agraciados Pablo añade su propio testimonio: (finalmente a mí como abortivo se me apareció) ${ }^{25}$.

Entre los corintios, de tradición helenística, había fuertes dudas sobre la resurrección, Pablo se siente, pues, obligado a confesarla y a explicarla, aduciendo testimonios y circunstancias objetivas: a la muerte y sepultura de Jesús se contrapone su resurrección y la aparición a Pedro, a Santiago y a tantos otros, de los cuales algunos todavía viven, o sea, quien dude o quiera cerciorarse sobre ella podría preguntar a estos. Por otra parte, la expresión "según las Escrituras" relaciona el hecho con el AT. Es un evento que pertenece a la

${ }^{25}$ La antigüedad de los versículos (3-7) está generalmente aceptada por la exegesis. Pablo escribe la primera carta a los Corintios el año 56-57, o sea, a unos veinticinco años de que sucediera lo que allí se testimonia, pero además dice que él lo recibió, por tanto, ya debió circular unos años después de la muerte de Jesús. 
historia salvífica de Dios con su pueblo: "murió por nuestros pecados". Por tanto - continúa Pablo - "si Cristo no resucitó vana es nuestra fe, aún estáis en vuestros pecados. Y hasta los que murieron en Cristo perecieron" (1Cor 15,17-18). Ante tal eventualidad, Pablo se reafirma en su fe: "Pero no, Cristo ha resucitado de entre los muertos como primicia de los que mueren"(1Cor 15,20). "Como en Adán todos mueren, así también en Cristo somos todos vivificados" (1Cor 15,22). "El que resucitó a Cristo Jesús de entre los muertos dará también vida a vuestros cuerpos mortales por virtud de su Espíritu, que habita en vosotros" ( $\mathrm{Rm} \mathrm{8,11).}$

¿Cómo se produjo este cambio tan radical en Saulo de Tarso? Para él, Jesús de Nazaret no podía ser el Mesías anunciado por las Escrituras. Un Mesías muerto en la cruz era, como ya se ha subrayado, impensable; quien ha sido colgado del madero estaba bajo la maldición de Dios (Dt 21,23). Comenzó por perseguir a Esteban, a quien consideraba como un promotor del cristianismo que atribuye honores divinos a Jesús y por tanto una amenaza para el monoteísmo hebraico. Es muy posible que este odio mortal a los cristianos fuese también una forma de compensar sus dudas interiores y sus remordimientos por lo que estaba emprendiendo, hasta que ya cerca de Damasco tiene lugar un suceso extraordinario, que Lucas comenta en los Hechos de los Apóstoles en tres relatos distribuidos en los capítulos 9,12 y 26. Los tres pasajes narran este hecho como una teofanía: Saulo quedó cegado por una luz intensísima, más radiante que la del mediodía en que tuvo lugar; una voz le interpela: Saulo, Saulo, ¿por qué me persigues?; y cuando él responde: ¿quién eres, Señor?, oye esta respuesta: Yo soy Jesús a quien tu persigues.

Es un encuentro entre Jesús y Pablo en el que se descubre la identidad de ambos, de modo que a Pablo se le abren los ojos para comprender realmente que el Jesús crucificado sí es el Mesías. Pero esto llevaba consigo, como ya hemos visto, interpretar la Escritura de un modo nuevo respecto a la tradición judaica, de manera que sus valores fundamentales cambiaban de forma radical: todo lo que antes eran ganancias, lo consideró pérdida ("basura"), al lado de lo grande que es haber conocido personalmente a Cristo Jesús (Fil 3,7-9):

"Cuando Aquel que me separó desde el seno de mi madre y me llamó por su gracia tuvo a bien revelar en mí a su Hijo, para que le anunciase entre los gentiles, al punto, sin perder consejo ni a la carne ni a la sangre, sin subir a Jerusalén donde los Apóstoles anteriores a mí, me fui a Arabia de donde nuevamente volví a Damasco. Después, al cabo de tres años, subí a Jerusalén a entrevistarme con Cefas, y con él permanecí quince días" (Gal 1, 15-17).

Las dos fuentes, los Hechos de los Apóstoles y las Cartas de Pablo, convergen en lo fundamental: el Resucitado se apareció a Pablo, lo llamó al apostolado, con la misión de testimoniar el Evangelio, en particular a los no ju- 
díos, no como consecuencia de una larga evolución personal, sino como una aparición-vocación que comprometía toda su vida. Resulta más que oportuno que Ignacio lo haya puesto en los Ejercicios como ejemplo de la elección "por el primer tiempo": "es cuando Dios nuestro Señor así mueve y atrae la voluntad, que, sin dubitar ni poder dubitar, la tal ánima devota sigue a lo que es mostrado, así como San Pablo y San Mateo lo hicieron en seguir a Cristo nuestro Señor" (EE 175).

La elección vocacional constituye, como es sabido, el centro de los Ejercicios, lo que les da unidad y dinamismo, pero no hay que perder de vista el paradigma neotestamentario en que Ignacio la coloca: si se acepta o se elige lo que el creyente siente que Dios quiere de él, es precisamente porque Dios primero lo ha propuesto. No se trata de elegir según el arbitrio de cada uno, movido solo por un acto natural, ético o psíquico, sino sobre todo de la aceptación de la iniciativa divina acerca de la libertad del creyente: "Que el Señor nos quiera dar su gracia para que su santísima voluntad siempre sintamos, y aquella enteramente la cumplamos". Así concluye Ignacio muchas de las siete mil cartas que de él han llegado hasta nosotros. La aceptación de la voluntad de Dios, que la elección vocacional implica, se decide ciertamente una vez por todas, pero ello no quiere decir que esté completamente realizada, sino que la elección es el comienzo de un proceso de búsqueda, de un crecimiento del creyente en su peculiar configuración con Cristo crucificado y glorioso ${ }^{26}$.

${ }^{26}$ R. GARCía MATEO, "Cristocentrismo de la elección y misión en los ejercicios ignacianos": ATG 78 (2015) 5-26. 